\title{
Effect of Transtheoretical Model Based Smoking Cessation Program on High School Students
}

Erol $\mathrm{S}^{1}$, Balci $\mathrm{AS}^{*_{2}}$, and Sisman $\mathrm{FN}^{3}$

${ }^{1}$ Associate Professor, Marmara University Nursing Health Department, Istanbul, Turkey

${ }^{2}$ Research Assistant, Marmara University Nursing Health Department, Istanbul, Turkey

${ }^{3}$ Assistant Professor, Marmara University Nursing Health Department, Istanbul, Turkey

*Corresponding author: Balci AS, Research Assistant, Marmara University Nursing Health Department, Basibuyuk Campus, Matepe, Istanbul, Turkey, Tel: +902163302070/1174, Fax: 02163302073, E-mail: ayses_18_9@hotmail.com

Citation: Erol S, Balci AS, Sisman FN (2018) Effect of Transtheoretical Model Based Smoking Cessation Program on High School Students. J Nutr Health Sci 5(3): 301. doi: 10.15744/2393-9060.5.301

Received Date: March 27, 2018 Accepted Date: September 11, 2018 Published Date: September 13, 2018

\begin{abstract}
Aim: The aim of this study is to evaluate the effect of Transtheoretical Model (Stage of Change Model) based smoking cessation program on among high school students.

Method: The study was conducted with 200 students at a high school by using the pretest-posttest quasi-experimental study design with single group. The data were collected by using questionnaire of demographic characteristics, Fagerström Tolerance Questionnaire, Stages of Change Questionnaire, Decisional Balance Scale and Self-Efficacy Scale. Motivational interviews were conducted with a semistructured protocol including six sections in accordance with the strategies of behaviour change stages. Five sessions were carried out for each groups.

Results: The students had an average age of $16.49 \pm 1.13$ and while $12 \%$ were female, $88 \%$ were male. At the end of the program, the students showed a statistically significant progress in the change stages of smoking cessation and $26.5 \%$ of them quitted smoking.

Conclusions: As the change stages progressed, the scores of Decisional Balance sub scale Coping Pros and mean scores of the subscales Habit Strength and Weight Control of Self-Efficacy Scale scores increased in a statistically significant $(\mathrm{p}<.01)$.

Keywords: Adolescent; Smoking cessation; Motivational interview; Transtheoretical model
\end{abstract}

\section{Introduction}

The use of tobacco is a global problem and one of the main causes of preventable death [1]. Approximately 6 million people die every year due to diseases caused by the use of tobacco [2,3]. Globally, $6.8 \%$ of girls and $36.1 \%$ of boys younger than 15 years smoke [4], and 82.000-99.000 young people start smoking every day [5].

Accordingly Turkey Health Interview Survey (2016) study, smoking rate in Turkey was 40.1\% in males, $13.3 \%$ in females and 26.5\% in adolescents [6]. In Turkey, Global Youth Tobacco Survey (GYTS) was conducted in 2003, 2008 and 2009. According to GYTS 2003; the rate of smoking was $6.9 \%$ among youth, $9.4 \%$ among boys and 3.5\% among girls. According to the results of GYTS 2009; the rate of smoking was $8.4 \%$ among youth, $10.2 \%$ among boys, and 5.3\% among girls. Smoking increased $1.5 \%$ compared to 2003. The results of the study revealed that the frequency of smoking keeps increasing in the age group of 13-15 years compared to other age groups $[2,7-9]$.

The most important regulations on tobacco control in Turkey issued Law on Tobacco and Tobacco Products and the Prevention of Damage at 2008. Scope of the law at 2009, smoking is prohibited in closed spaces (coffee shops, restaurants, cafes, bars, recreational facilities, etc.) [10]. After legal regulation in a study about on the frequency of smoking university students found that indoor smooking restriction law did not effect smoking habit among students [11]. Similirlarly, Tan et al. (2011) found their study smoking ban law was not deterrent for nursing students to give up smoking [12]. The effect of legal regulations is mainly towards reducing daily consumption, and there are different regulations related to quitting. 
Behaviour of smoking that starts with curiosity and trial in this period transforms into a dependency in youth and adulthood $[13,14]$. The reasons for adolescents to start smoking are different from adults and they comprise a more sensitive group in terms of dependency [15-17]. Smoking is considered one of the "leading causes of preventable death globally". Firstly, the cigarette smoke consists of different tars that cause lung cancer, heart attacks, chronic obstructive pulmonary disease, erectile dysfunction and cardio vascular diseases [18-20]. In addition to active smoking, exposure to cigarette smoke in closed areas other than selfhelp has been shown to be as important as active cigarette smoking in the development of passive smoking [21]. Adolescents who are heavy smokers and having parents and a best friend who smoke are more likely than others to have asthma symptoms [22].

The reasons that adolescents start smoking are different from those of adults, and adolescents comprise a more sensitive group in terms of dependency $[13,14,23]$.

In order to prevent adolescents from starting smoking, it is necessary to implement multidimensional regulations involving adolescents [15].

Transtheoretic model (TTM) also known as 'stages of change', was developed by Prochaska and DiClemente in 1982, the model was first applied to smoking behavior to validate the model. TTM consist of 4 components: stage of change (precontemplation, contemplation, preparation, action, and maintenance), which explains an individual's thoughts and behaviors regarding how to change behavior; processes of change, which explains what methods are used by the individual while changing behaviors; selfefficacy, which analyzes the self-confidence of the individual regarding how long she/he will be able to resist the desire to smoke; and decisional balance, which explains the pros and cons of change [16].

The aim of this study was to evaluate the effect of TTM based smoking cessation program among high school students.

\section{Materials and Methods}

\section{Setting and Participants}

The study was conducted using a quasi-experimental design with one-group pretest-posttest. The study was conducted at a technical high school in Istanbul, Turkey, between September 2014 and September 2015. There were 200 grade 9-12 students who had smoked every day within the last 30 days and signed the written consent forms with their families and were included in the study.

\section{Data Collection}

Pretest-posttest data of the study were collected by applying the Fagerström Tolerance Questionnaire (FTQ) for Nicotine Dependence, Stage of Chance Questionnaire (SCQ), Decisional Balance Scale (DBS), and Self-Efficacy Scale (SES). The data collection tools were applied in the students' classes in cooperation with the teachers. The pretest data were applied one week before the program. At the end of the program posttest data were collected in the students' classes.

Sociodemographic characteristics form: The form included 14 questions on the age, sex, and reason for smoking, as well as information on the student's family and friends.

Fagerström Tolerance Questionnaire (FTQ): This questionnaire developed by Fagerström in 1972 and assesses the nicotine dependence level of individuals and was adapted into the Turkish language by Uysal et al. (2004) (cronbach's alpha of the FTQ was 0.70) [17]. The test is an assessment instrument that consists of six questions with different scores and determines the dependence level as very low (0-2 points), low (3-4 points), moderate (5 points), high (6-7 points), and very high (8-10 points).

Stage of Chance Questionnaire (SCQ): The SCQ was developed by Prochaska and DiClemente (1983) for the purpose of identifying the change stages of smoking behavior and was adapted into the Turkish language by Erol and Erdogan (2008). The questionnaire asks about the smoking behavior of individuals [24]. They are said to be in the stage of "precontemplation" if they do not consider quitting smoking within the next six months, "contemplation" if they consider quitting smoking within the next six months, "preparation" if they consider quitting smoking within the next one month, "action" if they have not smoked for less than six months, and "maintenance" if they have not smoked for more than six months.

Decisional Balance Scale (DBS): This scale was adapted for use in adolescents by Pallonen et al. (1998). A 5-point likert scale with 12 items, the scale measures perceptions of the pros and cons of behavior. It was adapted into the Turkish language by Erol and Erdogan (2008) [24]. The DBS has two subscales for adults and three subscales for adolescents: Social Pros, Coping Pros, Cons. High pros perception scores signify that they have not decided to quit smoking, whereas high cons perception scores signify that they have decided to quit smoking and there is a high chance of success.

Self-Efficacy Scale (SES): This scale was adapted for use in adolescents by Pallonen et al. (1998) and adapted into the Turkish language by Erol and Erdogan (2008). It is a 5-point likert scale with 8 items. The scale has four subscales, which are negative affect, positive social environments, habit strength and weight control. Higher scores signify higher self-efficacy [24].

\section{TTM Based Smoking Cessation Program}

According to TTM five stages are to be passed for behavior change. Motivational techniques are important for successful passing of a stage and should be structured for preparation to the next stage. After applying pretest data collection forms to 200 students 
included in the study, the researchers conducted motivational interviews (MI). The first author was trained on MI, wrote her doctoral dissertation on the subject, and she has an international article published on this subject [24]. The first author trained the other researchers on MI techniques before the start of the program.

\section{Motivational Interviews}

A protocol involving semi-structured consultancy instructions was prepared before the motivational interviews [13,25]. The protocol consisted of six parts as; establishing relationships ${ }_{(1)}$, exploring pros and cons of smoking ${ }_{(2)}$, giving personalized feedback $_{(3)}$, imagining the future ${ }_{(4)}$, setting objectives (goals) $)_{(5)}$, increasing the cons perception and decreasing the pros perception of smoking ${ }_{(6)}$. Motivational Interviews based on stages of change (The Transtheoretical Model), five sessions and 45 minutes for each student groups. During the motivational interviews, questions were asked for making the students recognise pros and cons of smoking cessation. They were asked questions to reveal their conflicting emotions regarding smoking cessation. The possible obstacles in their action plan aimed at smoking cessation and the strategies to be followed for overcoming the obstacles were determined. The students were asked about their personal characteristics and personal past successes in order to increase their self-efficacy and contribute to their skill of change. At the end of each session, the interviews were summarized for students and they were given a personalized feedback $[24,25]$.

\section{Ethical Considerations}

A signed written informed consent form was obtained from all of the students and parents who participated in the study. Institutional permission was obtained from the institution where the study was conducted.

\section{Data Analysis}

The data of the study were analyzed using Statistical Program Software System 16.0 (SPSS 16.0; Chicago, USA). Demographic characteristics were evaluated with descriptive statistical analysis. Wilcoxon's test was used to assess the effect of the program on the study group pre-and post-tests. The scale scores were compared according to change stages via the Kruskall Wallis test. Bonferroni correction and the Mann Whitney $U$ test were performed to assess between-group differences. In the analysis of the data, $\mathrm{p}<0.05$ was considered significant.

\section{Results}

\begin{tabular}{|c|c|c|c|}
\hline Characteristics & Category & Case (n) & (\%) \\
\hline \multirow{3}{*}{ Age (year) } & $14-17$ & 152 & 76.0 \\
\hline & $18-20$ & 48 & 24.0 \\
\hline & Mean \pm SD & \multicolumn{2}{|c|}{$16.49 \pm 1.13$} \\
\hline \multirow{2}{*}{ Gender } & Girl & 24 & 12.0 \\
\hline & Male & 176 & 88.0 \\
\hline \multirow{4}{*}{ Second-hand smoking } & Mother & 72 & 36.0 \\
\hline & Father & 111 & 55.5 \\
\hline & Sister/brother & 45 & 22.5 \\
\hline & Friends & 178 & 89.0 \\
\hline \multirow{4}{*}{${ }^{\star}$ Reason for smoking } & Peer pressure & 123 & 61.5 \\
\hline & Stress & 92 & 46.0 \\
\hline & Wonder & 42 & 21.0 \\
\hline & Emulation & 14 & 7.0 \\
\hline \multirow{5}{*}{$\begin{array}{c}\text { Nicotine Dependency } \\
\text { Level } \\
(\mathbf{n}=192)\end{array}$} & Very low & 88 & 44.0 \\
\hline & Low & 44 & 22.0 \\
\hline & Moderate & 25 & 12.5 \\
\hline & High & 24 & 12.0 \\
\hline & Very high & 11 & 5.5 \\
\hline
\end{tabular}

${ }^{\star}$ More than one option is possible.

$\mathrm{n}=$ number of participation, $\%=$ percent

$\mathrm{SD}=$ standard deviation

Table 1: Main characteristics at baseline $(n=200)$

The students had an age average of $16.49 \pm 1.13$ years, and $12 \%$ were female, $88 \%$ were male. Before the application, $42.5 \%$ of the students were in the stage of precontemplation, $32.5 \%$ in contemplation, and $25 \%$ in preparation. According to the FTQ, the dependence levels were determined as very low for $44 \%$ of the participants, low for $22 \%$, moderate for $12.5 \%$, high for $12 \%$, and very high for 5.5\%. Regarding parental smoking, 36\% of the mothers and 55.5\% of the fathers smoked. The first reason given for smoking was peer pressure (61.5\%), which was followed by stress (46\%) (Table 1). 
Before program $42.5 \%$ of the students were in the stage of precontemplation stage, this rate decreased to $12.5 \%$ after program $\left(\mathrm{kwx}^{2}=38.65 ; \mathrm{p}=.00\right)$; while $32.5 \%$ of the students were in the stage of contemplation before program, this rate decreased to $26.5 \%$ after program $\left(\mathrm{kwx}^{2}=3.90 ; \mathrm{p}=0.04\right), 25 \%$ of the students were in the stage of preparation before program, this rate decreased to $34.5 \%$ after program $\left(\mathrm{kwx}^{2}=11.21 ; \mathrm{p}=.00\right)$ (Table 2$)$.

\begin{tabular}{|c|c|c|c|c|c|l|}
\hline Stage of change at baseline & \multicolumn{2}{|c|}{ Pre-test } & \multicolumn{2}{c|}{ Post-test } & \multicolumn{2}{|c|}{ Statistic } \\
\hline & $\mathbf{n}$ & $\%$ & $\mathbf{n}$ & $\mathbf{\%}$ & $\mathbf{x}^{\mathbf{2}}$ & $\mathbf{p}$ \\
\hline Precontemplation stage & 85 & 42.5 & 25 & 12.5 & 38.65 & $\mathbf{. 0 0}$ \\
\hline Contemplation stage & 65 & 32.5 & 53 & 26.5 & 3.90 & $\mathbf{. 0 4}$ \\
\hline Preparation stage & 50 & 25 & 69 & 34.5 & 11.21 & $\mathbf{. 0 0}$ \\
\hline Action stage & - & - & 53 & 26.5 & & \\
\hline
\end{tabular}

$\mathrm{x}^{2}=$ chi-square test, $\mathrm{n}=$ number of participation

$\mathrm{p}=$ statistical significant level

Table 2: The change stages of the students concerning smoking cessation before and after the motivational interviews

There was a significant decrease in the FTQ scores of the students after the program $(\mathrm{Z}=4.89 ; \mathrm{p}=.00)$. There was no statistically significant difference between the mean scores of the DBS subscales Social Pros and Coping Pros before and after program $(p>0.05)$. There was a difference between in mean scores of the DBS subscale Cons Perception before and after the program. Cons perception concerning smoking increased in a statistically significant way after the program $(Z=2.46 ; p=.01)$. There was no statistically significant difference in the total score or in the subscale mean scores of the SES before and after the program ( $\mathrm{p}>0.05$ ) (Table 3).

\begin{tabular}{|c|c|c|c|c|c|}
\hline \multirow{2}{*}{\multicolumn{2}{|c|}{ TTM constructs }} & Pre-test & \multicolumn{2}{c|}{ Post-test } & \multicolumn{2}{c|}{ Statistics } \\
\cline { 3 - 6 } & FTQ & Mean \pm SD & Mean \pm SD & Z & p \\
\hline \multirow{4}{*}{ DBS } & Social Pros & $4.31 \pm 2.55$ & $2.35 \pm 2.27$ & 4.89 & .00 \\
\cline { 2 - 6 } & Coping Pros & $8.25 \pm 3.22$ & $7.72 \pm 3.50$ & 0.47 & .63 \\
\cline { 2 - 6 } & Cons & $18.44 \pm 7.85$ & $26.76 \pm 5.13$ & 2.46 & 0.01 \\
\hline \multirow{7}{*}{ SES } & Negative Affect & $5.67 \pm 2.58$ & $5.72 \pm 2.41$ & 0.70 & .47 \\
\cline { 2 - 6 } & Positive Social Environ- & $5.89 \pm 2.26$ & $5.74 \pm 2.23$ & 086 & .89 \\
\cline { 2 - 6 } & ments & $5.94 \pm 2.40$ & $5.90 \pm 2.58$ & 0.10 & .92 \\
\cline { 2 - 6 } & Habit Strength & $5.98 \pm 3.33$ & $6.17 \pm 3.31$ & 0.76 & .44 \\
\cline { 2 - 6 } & Weight Control & $23.53 \pm 7.41$ & $23.55 \pm 8.13$ & 0.80 & .42 \\
\hline
\end{tabular}

$\mathrm{Z}=$ Wilcoxon's test, $\mathrm{p}=$ statistical significant level, $\mathrm{SD}=$ standard deviation

TTM=Transtheoretical Model

FTQ=Fagerström Tolerance Questionnaire, DBS=Decisional Balance, SES=Self Efficiency Scale

Table 3: The comparison of the total scores of the students in FTQ, DBS and SES before and after MI

\begin{tabular}{|c|c|c|c|c|c|c|c|}
\hline \multirow[b]{2}{*}{$\begin{array}{c}\text { TTM } \\
\text { Constructs }\end{array}$} & & \multicolumn{4}{|c|}{ Stages of change } & \multirow{2}{*}{$\begin{array}{c}\text { Statistics } \\
\mathbf{x}^{2}\end{array}$} & \multirow{2}{*}{$\begin{array}{c}\text { Post hoc test } \\
\text { Z }\end{array}$} \\
\hline & & $\begin{array}{l}\mathrm{PC}(\mathrm{n}=25) \\
\text { mean } \pm \text { SD }\end{array}$ & $\begin{array}{l}C(n=53) \\
\text { mean } \pm S D\end{array}$ & $\begin{array}{l}P R(n=69) \\
\text { mean } \pm S D\end{array}$ & $\begin{array}{l}A(n=53) \\
\text { mean } \pm \text { SD }\end{array}$ & & \\
\hline FTQ & & $4.84 \pm 2.49$ & $2.32 \pm 1.89$ & $2.85 \pm 2.03$ & $0.58 \pm 1.21$ & $67.30^{* * *}$ & $\mathrm{~A}<\mathrm{PC}, \mathrm{C}, \mathrm{PR}$ \\
\hline \multirow{2}{*}{ DBS } & Social Pros & $5.33 \pm 2.61$ & $4.94 \pm 2.62$ & $4.88 \pm 2.47$ & $4.59 \pm 2.32$ & 1.46 & \\
\hline & Coping Pros & $9.00 \pm 3.50$ & $8.27 \pm 3.19$ & $8.11 \pm 3.61$ & $6.03 \pm 3.12$ & $17.53^{\star * *}$ & $\mathrm{~A}<\mathrm{PC}, \mathrm{P}, \mathrm{PR}$ \\
\hline \multirow{6}{*}{ SES } & Cons & $22.62 \pm 7.41$ & $25.17 \pm 5.42$ & $26.42 \pm 4.68$ & $26.28 \pm 5.61$ & 7.29 & \\
\hline & Negative Affect & $6.40 \pm 2.58$ & $6.35 \pm 2.14$ & $6.01 \pm 2.22$ & $6.35 \pm 2.95$ & 1.16 & \\
\hline & $\begin{array}{c}\text { Positive Social Environ- } \\
\text { ment }\end{array}$ & $6.44 \pm 1.75$ & $5.90 \pm 1.93$ & $6.33 \pm 2.09$ & $6.28 \pm 2.96$ & 1.73 & \\
\hline & Habit Strength & $5.04 \pm 2.82$ & $4.35 \pm 2.63$ & $5.47 \pm 2.85$ & $6.16 \pm 3.45$ & $9.11^{\star *}$ & $\mathrm{~A}>\mathrm{PR}, \mathrm{PC}, \mathrm{C}$ \\
\hline & Weight Control & $2.36 \pm 3.20$ & $4.05 \pm 3.97$ & $5.40 \pm 4.15$ & $5.41 \pm 4.21$ & $13.41^{\star * *}$ & $\mathrm{~A}>\mathrm{PR}, \mathrm{C}, \mathrm{PC}$ \\
\hline & Combined & $23.64 \pm 6.75$ & $24.96 \pm 6.70$ & $24.96 \pm 6.70$ & $22.32 \pm 0.63$ & 2.58 & \\
\hline
\end{tabular}

$\mathrm{PC}=$ Precontemplation, $\mathrm{C}=$ Contemplation, $\mathrm{PR}=$ Preparation, $\mathrm{A}=$ Action

TTM= Transtheoretical Model

FTQ= Fagerström Tolerance Questionnaire, DBS=Decisional Balance, SES=Self Efficiency Scale

$\mathrm{x}^{2}=$ Kruskall Wallis test ${ }^{* *} \mathrm{p}<0.01,{ }^{* *} 0.001$ Mean differences for the Bonferroni corrected Mann-Whitney U tests pair wise comparisons ( $\mathrm{p}<0.012$ ).

$\mathrm{Z}=$ Man Whitney $\mathrm{U}$ test

Table 4: The comparison of the post-test scores of the TTM constructs according to stages of change 
FTQ scores decreased in a statistically significant way as they progressed through the stages of change ( $\mathrm{p}<.001)$. The students' Coping Pros scores showed a significant difference according to the stages of change. The scores decreased in a statistically significant way as they progressed through the stages of change $(\mathrm{p}<.001)$ (Table 4$)$.

The students' mean scores in the Habit Strength and Weight Control subscales of the SES increased in a statistically significant way as they progressed through the stages of change $(\mathrm{p}<.01, \mathrm{p}<.00)$. The post hoc test determined that the students in the action stage had the highest score in both subscales. There was no statistically significant difference in the combined mean scores of the SES and the stages of change ( $\mathrm{p}>.05)$ (Table 4$)$.

\section{Discussion}

As a result of this study, which examined the effect of TTM based smoking cessation among high school students, it was determined that the program was effective, and $26.5 \%$ of the students quit smoking. Smoking cessation was evaluated based on personal statements, and the cessation rates were confirmed by verbal feedbacks from families and teachers. Related studies that were conducted Turkey and abroad [24,26,27] have suggested that motivational interviews were effective for smoking cessation in adolescents, and reported that smoking cessation resulting from use of this method varied between 5\% and 59\%. Also, in order to expand the coverage of smoking cessation interventions to high school students, it is important to integrate e-health interventions with motivational interviews and conventional clinical model [28].

In the literature, nicotine dependence is stated as one of the greatest obstacles for adolescents to quit smoking [27]. In this study, the dependence levels of the students were evaluated using the nicotine dependence scale; however, saliva cotinine and other objective measurements were not conducted. Two different studies found a decrease in the nicotine dependence scores of adolescents following the motivational interviews, which supports the results of the present study [29].

While the percentage of the students in the stage of precontemplation decreased, that of the students in the stages of preparation and action increased. In parallel with the results of the present study, in their studies, Gungormus and Erci (2012) determined that the students progressed through the stages of change after the motivational interviews [30].

At the end of this study, Coping Pros score was the lowest in the stage of action, in accordance with the structure of the model. This result showed that motivational interviews increased the skills of students to cope with negative feelings. In their study, Ha and Choi (2012) determined that adolescents had decreased Coping Pros scores after the motivational interviews [31].

At the end of the study, the scores of the perception of the cons of smoking increased compared to the period before the study. In their study, Huang et al. [2015] determined that adolescents had an increased perception of the cons of smoking after the motivational interviews [32]. Erol and Erdogan (2008) determined that students in the motivation group had an increased cons perception as they progressed in change stages [24]. Additionally, having awareness of smoking's adverse effects and being frequently supervised by the authority (e.g. no smoking enforcement in public areas) were found to be associated with a greater motivation to quit [33].

In this study, SES subscale Habit Strength scores increased to students. Similar to the results of this study, Ha and Choi (2012) determined that Habit Strength scores increased as students progressed through the stages of change [31].

\section{Limitations}

The limitations of this study were that smoking cessation behavior was dependent on self-report, an objective measurement could not be performed, there was no control group, and no long-term follow-up was done after the program ended. Other studies explored the relationship between smoking and quality of life [34], as well as comorbid alcohol misuse [35], but these two factors were not explored in the current study.

\section{Conclusion}

At the end of the study TTM based program were found to be effective in smoking cessation. The students showed increased scores in the perception of the cons of smoking. As they progressed through the stages of change, scores pertaining to nicotine dependence and coping pros decreased. Self-efficacy scores relating to weight control and habit strength increased. It is also necessary to conduct long-term and extensive studies comprising the school, family, and friends of students and developing their coping skills.

\section{References}

1. Beaglehole R, Bonita R, Horton R, Adams C, Alleyne G, et al. (2011) Priority actions for the noncommunicable disease crisis. Lancet 377: 1438-47.

2. The Ministry of Health of Turkey (2010) Global Adult Tobacco Survey Turkey Report 2010. Ankara, Turkey.

3. WHO (2011) WHO Report on the global tobacco epidemic 2011 warning about the dangers of tobacco. Geneva, Switzerland.

4. WHO (2012) Global health observatory data repository 2012. Geneva, Switzerland.

5. Mackay J, Eriksen M, Shafey O (2012) The tobacco atlas. Am J Epidemiol 176: 1193. 
6. Turkey Health Survey (2016) Turkey.

7. WHO (2012) Public Health Institution of Turkey, Global adult tobacco survey Turkey (GATS) 2012. Republic of Turkey Ministry of Health, Ankara, Turkey. 8. Erguder T, Cakır B, Aslan D, Warren CW, Jones NR, et al. (2008) Evaluation of the use of global youth tobacco survey data for developing evidence-based tobacco control policies in Turkey. BMC Public Health 8: 4-9.

9. Erguder T, Polat H, Arpad C, Khoury RN, Warren C, Lee J, et al. (2012) Linking global youth tobacco survey data to tobacco control policy in Turkey-2003-2009. Cent Eur J Public Health 20: 87-91.

10. The Law on the Prevention of Tobacco Product Losses (1996) The Law On Prevention And Control Of Hazards Of Tobacco Products(1). 5: 36.

11. Topcu B, Unsal C, Gazeloglu C, Aktas S (2014) The effect of indoor smoking restriction law on smoking habit of university students. Int J Basic Clin Med 2: 24-31.

12. Tan M, Arikan D, Akgun Sahin Z (2011) The effect of smoking ban in enclosed places on nursing students' attitudes to giving up smoking. J Anatolia Nurs Health Sci 14: 47-51.

13. Sussman S, Sun P, Dent C (2006) A meta-analysis of teen cigarette smoking cessation. Health Psychol 25: 549-57.

14. Lynes D, Lynes A (2012) Strategies to help adolescents stop smoking, Nursing practice, discussion teenage smoking. Nurs Times 8: 12-14.

15. Gottfredson DC, Kearley BW, Bushway SD (2008) Substance use, drug treatment, and crime: An examination of intra-individual variation in a drug court population. J Drug Issues 38: 601-30.

16. Prochaska JO, Diclemente CC, Norcross JC (1992) In search of how people change applications to addictive behaviors. Am Psychol 47: 1102-14.

17. Uysal MA, Kadakal F, Karsidag C, Bayram NG, Uysal O, et al. (2004) Fagerström test for nicotine dependence: reliability in a Turkish sample and factor analysis. Tuberk Toraks 52: 115-21.

18. Action on Smoking and Health (2016) Smoking statistics: Illness and death. London, England.

19. WHO (2013) WHO report on the global tobacco epidemic, 2013: enforcing bans on tobacco advertising, promotion and sponsorship. Geneva, Switzerland.

20. West R (2017) Tobacco smoking: Health impact, prevalence, correlates and interventions. Psychol Health 32: 1018-36.

21. Gunlemez A, Er I, Baydemir C, Arisoy A (2018) Effects of passive smoking on lung function tests in preschool children born late-preterm: a preventable health priority. J Matern.-Fetal Neonatal Med 1: 1-6.

22. Mak KK, Ho RC, Day JR (2012) The associations of asthma symptoms with active and passive smoking in Hong Kong adolescents. Respir Care 57: $1398-404$.

23. Garrison M, Christakis D, Ebel B, Wiehe S, Rivara F (2003) Smoking cessation interventions for adolescents: a systematic review. Am J Prev Med 25: 363-67.

24. Erol S, Erdogan S (2008) Application of a stage based motivational interviewing approach to adolescent smoking cessation: Transtheoretical model-based study. Patient Educ Couns 72: 42-8.

25. Miller WR, Rollnick S (2013) Motivational Interviewing: Helping People Change. 3rd (Edn.) Newyork.

26. Jensen CD, Cushing CC, Aylward BS, Craig JT, Sorell DM, et al. (2011) Effectiveness of motivational interviewing interventions for adolescent substance use behavior change: A meta-analytic review. J Consult Clin Psychol 79: 433-40.

27. Stephens S, Cellucci T, Gregory J (2004) Comparing stage of change measures in adolescent smokers. Addict Behav 29: 759-64.

28. Tran BX, Le XTT, Nguyen PN, Le QNH, Mai HT, et al. (2018) Feasibility of e-health interventions on smoking cessation among Vietnamese active internet users. Int J Environ Res Public Health 15: E165.

29. Chun J, Bae YJ, Min SK (2012) Effectiveness of smoking cessation program for male adolescents in South Korea. Child Youth Serv Rev 34: 304-10.

30. Gungormus Z, Erci B (2012) Transtheoretical model-based education given for smoking cessation in higher school students. Southeast Asian J Trop Med Public Health 43: 1548-59.

31. Ha YS, Choi YH (2012) Effectiveness of a motivational interviewing smoking cessation program on cessation change in adolescents. J Korean Acad Nurs 42: 19-27.

32. Huang FF, Jiao NN, Zhang LY, Lei Y, Zhang JP (2015) Effects of a family-assisted smoking cessation intervention based on motivational interviewing among low-motivated smokers in China. Patient Educ Couns 98: 984-90.

33. Le XTT, To LT, Le HT, Hoang HD, Do KN, et al. (2018) Factors associated with cigarette smoking and motivation to quit among street food sellers in Vietnam. Int J Environ Res Public Health 15: 223.

34. Tran BX, Nguven HLT, Le QNH, Mai HT, Ngo C, et al (2017) Alcohol and tobacco use among methadone maintenance patients in Vietnamese rural mountainside areas. Addict Behav Rep 7:19-25.

35. Zhang MWB, Tran BX, Nguven HLT, Le HT, Long NH, et al. (2017) Using online respondent driven sampling for Vietnamese Youths' alcohol use and associated risk factors. Health Inform Res 23:109-118.

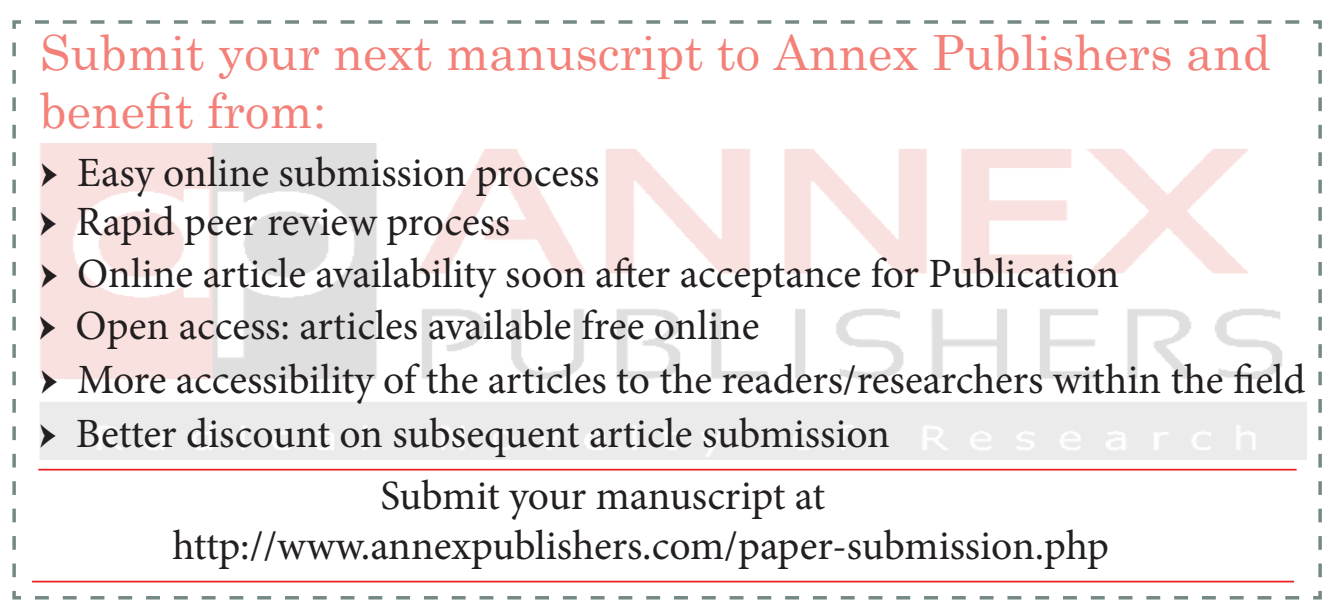

